\title{
PENGARUH CITRA MEREK DAN WORD OF MOUTH TERHADAP KEPUTUSAN PEMBELIAN SEPEDA MOTOR YAMAHA
}

\author{
HASTUTI HABIR \\ ZAKIYAH ZAHARA \\ FARID \\ Program Studi S1 Manajemen Fakultas Ekonomi Universitas Tadulako \\ Email: hastutiuti1234@gmail.com
}

\begin{abstract}
This research aims to find out and analyze the effect of brand image and word of mouth, either simultaneously or partially on the decision of purchasing Yamaha motorcycle in Bungku Tengah of Morowali Regency. This was a descriptive research with population of consumers of yamaha motorcycle in Bungku Tengah of Morowali Regency. Sample used was random sampling, in which 91 people selected as the sample. Data collection was questionnaire and it was analyzed using multiple linear regression analysis.The research result reveals that significant probability value of brand image variable $(0.002)<(0.05)$ so the brand image variable has a significant effect on the decision of purchasing, significant probability value of word of mouth $(0.087)>(0.05)$ so the word of mouth variable has no effect on the decision of purchasing. It means the brand image variable partially has a significant effect on decision of purchasing; however, word of mouth variable partially has no effect on kdecision of purchasing.
\end{abstract}

Kata kunci: Brand Image, Word of Mouth, Decision of Purchasing.

\begin{abstract}
ABSTRAKSI
Penelitian ini bertujuan untuk mengetahui analisi pengaruh citra merek dan word of mouth, baik secara simultan maupun parsial terhadap keputusan pembelian sepeda Motor Yamaha di Bungku Tengah Kabupaten Morowali Kecamatan. Jenis penelitian ini adalah deskriptif, Populasi penelitian ini adalah konsumen pengguna Motor Yamaha di Bungku Tengah Kabupaten Morowali. Teknik pengambilan sampel yang digunakan adalah Random Sampling, dan dengan tehnik tersebut 91 orang sebagai sampel. Teknik pengumpulan data yang di gunakan adalah angket, dan Teknik analisis data yang di gunakan adalah analisis regresi linier berganda.

Hasil penelitian menunjukkan bahwa, angka probabilitas signifikan variabel Citra Merek $(0,002)<$ $(0,05)$ sehingga variabel Citra Merek memiliki pengaruh yang signifikan terhadap keputusan pembelian, angka probabilitas signifikan variabel Word of Mouth $(0,087)>(0,05)$ sehingga variabel Word of Mouth tidak mempunyai pengaruh yang signifikan terhadap keputusan pembelian. Artinya variabel Citra Merek secara parsial berpengaruh signifikan terhadap keputusan pembelian, namun variabel Word of Mouth secara parsial berpengaruh tidak signifikan terhadap keputusan pembelian.
\end{abstract}

Kata kunci: citra merek, mulut ke mulut, keputusan pembelian

\section{PENDAHULUAN}

Era globalisasi saat ini membuat persaingan bisnis semakin tajam, baik pasar domestik maupun pasar global. Walaupun konsumen tetap ada namun daya beli mereka masih terbatas. Akibatnya konsumen menjadi semakin teliti dalam melakukan pembelian dan penentuan merek suatu produk yang mereka inginkan. keadaan tersebut mendorong perusahaan agar bisa menarik konsumen, menawarkan produk yang berkualitas dan memperhatikan merek yang disertai juga harga yang ekonomis. Konsumen dalam memilih suatu produk akan melalui tahap percobaan terlebih dahulu, pada tahap ini seringkali kosumen akan mencoba berbagai merek yang berbeda. Jika dirasakan merek tersebut cocok dan memenuhi apa yang diharapkan dari produk sejenis, maka konsumen akan terus mencari merek tersebut. Menurut Ismani (2008), tanpa citra merek yang kuat dan positif, sangatlah sulit bagi perusahaan untuk menarik pelanggan baru dan mempertahankan yang sudah ada. Brand atau merek adalah nama, istilah, tanda, simbol, ataupun kombinasinya yang mengidentifikasi suatu produk 
Habir, $\mathrm{H}$.

atau jasa yang dihasilkan oleh suatu perusahaan. Saat ini banyak konsumen yang mencari produk yang bisa membantu memudahkan kegiatannya sehari-hari, dalam hal ini adalah dibidang transportasi yaitu sepeda motor.

Selain perusahaan menjalankan strategi penjualan agar produknya dapat diterima di pasar, peran konsumen yang pernah memakai suatu produk merupakan hal yang perlu diperhatikan. Konsumen yang telah memakai suatu produk dan merasa puas akan produk tersebut, secara otomatis akan menceritakan dan merekomendasikan kepada orang lain, sehingga dapat menciptakan pembelian individu yang mendengarnya.

Komunikasi word of mouth (WoM), WoM memiliki kekuatan yang lebih besar dibanding dengan iklan dan bentuk promosi lain. Menurut Onbee Marketing Research (anak perusahaan Octovate Consulting Group) yang bekerjasama dengan majalah SWA, melakukan penelitian kepada 2000 konsumen di lima kota besar di Indonesia, dan menyimpulkan bahwa 89\% konsumen di Indonesia lebih mempercayai rekomendasi dari teman dan keluarga pada saat ingin membeli suatu produk (Suhartono, 2010:3).

Komunikasi Word of mouth (WoM) dan Citra Merek yang ada di Dealer CV Makmur Mandiri Motor yang tepatnya di Bungku Tengah, dari hasil penelitian sementara pada pengguna sepeda motor Yamaha terlihat sebuah fenomena bahwa konsumen yang telah merasakan atau menggunakan motor Yamaha akan menggambarkan atau menceritakan bahwa mereka puas atau tidak terhadap produk yang telah dibeli. Sehingga saat produk memiliki nilai positif akan memiliki peluang yang sangat besar untuk direkomendasikan konsumen kepada konsumen yang lainnya dan begitu juga sebaliknya saat produk dilempar kepasaran dinilai memiliki nilai negatif maka akan mendapatkan publikasi negatif oleh para konsumen. Dapat dilihat bahwa sebenarnya konsumen memiliki kemampuan dalam melakukan promosi suatu produk atau jasa secara tidak langsung. Promosi yang dilakukan oleh konsumen, biasanya akan memiliki kekuatan tersendiri dalam mempengaruhi orang lain. Promosi seperti ini dinamakan promosi dari mulut ke mulut (Word of mouth Marketing).

\section{KAJIAN LITERATURE DAN PENGEMBANGAN HIPOTESIS \\ Penelitian Terdahulu}

Jalivand dan Samiei (2012) Melakukan penelitian yang berjudul analisis pengaruh citra merek dan word of mouth terhadap keputusan pembelian sepeda motor Yamaha. Penelitian ini bertujuan untuk menguji sejauh mana pengaruh citra merek word of mouth terhadap keputusan pembelian. Pengumpulan data dalam penelitian tersebut menggunakan metode survey. Variabel yang diteliti dalam penelitian tersebut adalah WoM antar konsumen, Citra Merek, dan keputusan pembelian Konsumen. Sampel yang digunakan untuk diuji dalam penelitian tersebut adalah responden yang memliki pengalaman dalam konsumen pada agen industry mobil Khodro di Iran selama masa penelitian berlangsung sebanyak 341 responden.

Hasil yang diperoleh dari analisis penelitian tersebut adalah adanya pengaruh positif WoM terhadap citra merek, WoM memiliki pengaruh positif yang kuat terhadap niat beli konsumen, dan citra merek dapat mempengaruhi niat beli konsumen. Persamaan antara penelitian terdahulu dan penelitian saat ini terletak pada variabel bebas yaitu citra merek, variabel terikat yaitu WoM dan keputusan pembelian., instrumen penelitian yang akan menggunakan kuesioner, analisis data menggunakan aplikasi SPSS, dan skala pengukuran yang digunakan adalah Skala Likert. Perbedaan antara penelitian terdahulu dan penelitian saat ini terletak pada teknik pengambilan sampel, jumlah responden, objek penelitian, dan lokasi penelitian.

Ahmed (2004), melakukan penelitian yang berjudul "The Effect of Brand Image and Brand Identification on Brand Love and Purchase Decision Making : The Role of WOM. Pada penelitian kali ini meneliti salah satu aspek yang penting yang diperhatikan oleh perusahaan yaitu bagaimanan konsumen menyukai sebuah merek produk, yang kemudian akan memberikan efek positif yang disampaikan melalui komunikasi word of mouth yang akan memberikan pengaruh terhadap keputusan 
penggunaan produk dan jasa dari perusahaan tersebut. Kecintaan pada sebuah merek akan memberikan pengaruh besar terhadap keputusan penggunaan dengan menggunakan mediasi word of mouth. Penelitian kali ini menggunakan variabel independen yaitu kecintaan merek (brand love), WoM sebagai variabel mediasi dan keputusan penggunaan sebagai variabel dependen. Menggunakan data yang diambil dengan metode kuisioner yang disebarkan pada 150 responden. Persamaan penelitian Methaq dan peneliti saat ini yaitu pada variabel citra merek dengan variabel mediasi yaitu word-of-mouth yang berpengaruh pada pengambilan keputusan penggunaan atau pembelian. Perbedaannya yaitu terletak pada obyek dan juga teknik analisis data yang digunakan oleh peneliti.

\section{Manajemen Pemasaran}

Kotler dan Keller (2009:5) mendefinisikan manajemen pemasaran seni dan ilmu memilih pasar sasaran dan meraih, menciptakan, serta menumbuhkan pelanggan dengan menciptakan, menghantarkan dan mengkomunikasikan nilai pelanggan yang unggul. Konsep pemasaran suatu proses sosial dan manajerial yang di dalamnya individu dan kelompok mendapatkan apa yang mereka butuhkan dan inginkan dengan menciptakan, menukarkan, dan menukarkan produk dan jasa yang bernilai dengan pihak lain. Konsep ini bersandar pada empat pilar, yaitu pasar sasaran, kebutuhan pelanggan, pemasaran terpadu,dan profitabilitas.

\section{Citra Merek}

Menurut Kotler dan Keller (2009:172), citra merek adalah nama,istilah, lambang atau desain, atau kombinasinya yang dimaksudkan untuk mengidentifikasi barang atau jasa dari salah satu penjual atau kelompok penjual dan mendiferensisikan mereka dari pesaing. persepsi dan keyakinan yang dilakukan oleh konsumen, seperti tercermin dalam asosiasi yang terjadi dalam memori konsumen. Citra merek yang baik akan membentuk suatu keputusan pembelian produk atau jasa. Merek merupakan salah satu asset organisasi yang paling berharga (Fandy Tjiptono ,2012;263). Citra merek sebagai persepsi konsumen dan preferensi terhadap merek, sebagaimana yang direfleksikan oleh berbagai macam asosiasi merek yang ada dalam ingatan konsumen. Meskipun asosiasi merek dapat terjadi dalam berbagai macam bentuk tapi dapat dibedakan menjadi asosiasi performansi dan asosiasi imajeri yang berhubungan dengan atribut dan kelebihan merek. Merek memiliki karakteristik yang lebih luas daripada produk yaitu citra pengguna produk, country of origin, asosiasi perusahaan, brand personality, simbol-simbol dan hubungan merek atau pelanggan.

\section{Word Of Mouth (WoM)}

Harrison-Walker (2001:63) menyatakan bahwa terdapat tiga aspek yang membentuk word of mouth (WoM). Aspek pertama adalah antusiasme, yang meliputi frekuensi (seberapa sering individu terlibat dalam WoM dan jumlah interaksi. Aspek kedua adalah detail, atau berapa banyak yang dikatakan. Sapek ketiga adalah pujian, dari komunikasi WoM. Sebuah komunikasi informal diantara seorang pembicara yang tidak komersil dengan orang yang menerima informasi mengenai sebuah merek, produk, perusahaan atau jasa. Pelanggan yang puas dan tidak puas akan berbicara kepada teman, keluarga hingga rekan bisnis terhadap pengalamannya dalam menggunakan produk tersebut, sehingga word of mouth memiliki pengaruh dan berdampak yang tinggi terhadap pemasaran dibandingkan dengan aktifitas komunikasi lainnya (Ririn \& Mastuti, 2011:82).

\section{Keputusan Pembelian}

Menurut Peter dan Olson (2013:163) Keputusan pembelian adalah proses integritas yang dilakukan untuk mengkombinasikan pengetahuan guna mengevaluasi dua atau lebih alternatif dan memilih satu diantaranya. Struktur Keputusan Pembelian. Menurut Kotler (2009:184) keputusan pembelian konsumen akhir perorangan dan rumah tangga yang membeli barang dan jasa untuk konsumen pribadi Pengertian keputusan pembelian. Pengambilan keputusan merupakan suatu kegiatan individu yang secara langsung terlibat dalam mendapatkan dan mempergunakan barang yang ditawarkan. 
Habir, H.

\section{Hipotesis}

1. Citra Merek, Word of Mouth secara serempak berpengaruh positif dan signifikan terhadap keputusan pembelian Sepeda Motor Yamaha Studi pada Dealer CV Makmur Mandiri di Bungku Tengah Kabupaten Morowali.

2. Citra Merek berpengaruh positif dan signifikan terhadap keputusan pembelian Sepeda Motor Yamaha Studi pada Dealer CV Makmur Mandiri di Bungku Tengah Kabupaten Morowali.

3. Word of Mouth berpengaruh positif dan signifikan terhadap keputusan pembelian Sepeda Motor Yamaha Studi pada Dealer CV Makmur di Bungku Tengah Kabupaten Morowali.

\section{METODE PENELITIAN}

Penelitian ini adalah deskriptif kausal yang dilakukan untuk mengetahui data pengaruh citra merek dan word of mouth terhadap keputusan pembelian sepeda motor Yamaha di Bungku Tengah Kabupaten Morowali (Studi pada Dealer CV Makmur Mandiri di Kabupaten Morowali), responden dalam penelitian adalah para konsumen sepeda motor yamaha, yang memutuskan untuk pembelian sepeda motor yamaha mio, dengan cara memberikan kuesioner kepada yang bersangkutan. Adapun yang akan dibahas hanya pada seberapa besar pengaruh citra merek, word of mounth terhadap kepuasan pembelian sepeda motor Yamaha Dealer CV Makmur Mandiri di Kabupaten Morowali.

Penelitian ini dilakukan tepatnya di Bungku Tengah Kabupaten Morowali, di tujukan pada pengguna Sepeda Motor Yamaha Studi pada Dealer CV Makmur Mandiri di Bungku Tengah Kabupaten Morowali. Selain itu waktu yang dibutuhkan dalam penelitian ini selama kurang lebih 4 bulan, September 2017-Februari 2018.

Metode Pengumpulan Data terdiri dari observasi, wawancara dan kuesioner. Observasi disebut juga pengamatan, yang meliputi kegiatan pemantaun langsung kepada objek yang diteliti. Metode ini digunakan untuk mengetahui penerapan dalam pengguna Sepeda Motor Yamaha. Peneliti tinggal membubuhkan tanda $\sqrt{ }$ (check) pada kriteria yang sesuai. Lembar pengamatan diisi pada waktu kegiatan observasi. Wawancara adalah teknik pengamatan langsung dalam penelitian melalui pertanyaan-pertanyaan langsung kepada responden, wawancara merupakan alat pengumpulan data untuk memperoleh informasi langsung. Wawancara disini ditujukan kepada pengguna Motor Yamaha di Bungku Tengah Kabupaten Morowali. Wawancara dilakukan pada pengguna Motor bertujuan untuk melengkapi data yang tidak terdapat pada kuesioner. Kuesioner merupakan teknik pengumpulan data yang dilakukan dengan cara memberi seperangkat pernyataan tertulis kepada responden untuk di jawabnya. Kuesioner yang digunakan oleh peneliti sebagai instrumen penelitian, metode yang digunakan adalah dengan kuesioner tertutup. Instrument kuesioner harus diukur validitas dan reabilitas datanya sehingga penelitian tersebut menghasilkan data yang valid dan reliable Instrumen yang valid berarti instrument tersebut dapat dipergunakan untuk mengukur apa yang seharusnya diukur, sedangkan instrument yang reliable adalah instrumen yang apabila digunakan beberapa kali untuk mengukur objek yang sama akan menghasilkan data yang sama pula.

Selanjutnya proses pengolahan data yang diperoleh, maka metode analisis yang digunakan oleh peneliti adalah Metode Analisis Kuantitatif, metode ini digunakan untuk menganalisis data yang memerlukan pengukuran kuantitatif dengan menggunakan analisis statistic. Analisis statistik yang digunakan dalam penelitian ini adalah Regresi Linier Berganda yang diolah dengan program SPSS. Analisis regresi linier berganda untuk mengetahui seberapa besar citra merek dan word of mounth terhadap keputusan pembelian. Model regresi linier berganda terdapat variable independen $X_{1}, X_{2} \ldots X_{n}$, dengan variabel dependen $\mathrm{Y}$.

$$
\mathrm{Y}=\alpha+\beta_{1} \mathrm{X}_{1}+\beta_{2} \mathrm{X}_{2} \ldots .+\beta_{\mathrm{n}} \mathrm{X}_{\mathrm{n}}+€_{\mathrm{I}}
$$




\section{HASIL DAN PEMBAHASAN}

\section{Uji Normalitas Data}

Uji normalitas bertujuan mengkaji apakah dalam sebuah model regresi variabel dependent (terikat), independent (bebas) atau keduanya mempunyai distribusi normal atau tidak. Model regresi yang baik adalah distribusi data normal atau mendekati normal. Deteksi normalitas dilakukan dengan melihat penyebaran data (titik) pada sumbu diagonal dari grafik.

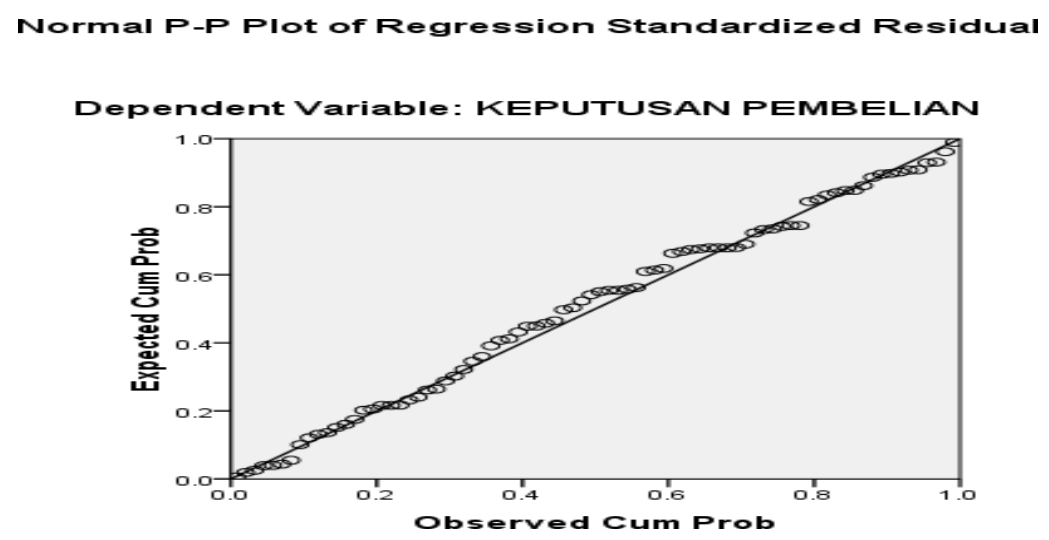

Gambar. 1 Kurva Normal P-Plot

Hasil uji normalitas data dapat dilihat pada titik sebaran data yang dihasilkan dalam penelitian ini sehingga dapat disimpulkan bahwa data dalam penelitian ini normal, dapat dilihat bahwa data menyebar disekitar garis diagonal, dan mengikuti arah garis diagonal, maka model regresi memenuhi asumsi normalitas.

\section{Uji Multikolinearitas}

Multikolinearitas dimaksudkan untuk mengetahui apakah diantara variabel bebas tidak saling berkolerasi atau tidak terdapat hubungan yang signifikan antara variabel bebas. Adanya korelasi yang tinggi diantara beberapa variabel bebas menyebabkan kita tidak dapat mengisolasi pengaruh individual dari variabel bebas terhadap variabel terikat

Tabel 1

Hasil Uji Multikolinearitas

\begin{tabular}{|l|c|c|}
\hline \multirow{2}{*}{\multicolumn{1}{|c|}{ Variable }} & \multicolumn{2}{c|}{ Collinearity Statistic } \\
\cline { 2 - 3 } & Tolerance & VIF \\
\hline Citra Merek &, 953 & 1.050 \\
\hline Word of Mouth &, 963 & 1.105 \\
\hline
\end{tabular}

Dapat diketahui bahwa hasil perhitungan Tolerance menunjukan tidak ada variabel independen yang memiliki nilai Tolerance kurang dari 0,10 yang berarti tidak ada korelasi antara variabel independen yang nilainya lebih dari 95\%. Demikian juga hasil perhitungan Variance Inflation Factors (VIF) besarnya nilai korelasi diantara variabel independen yang ada, menunjukkan bahwa korelasi diantara variabel-variabel independen (bebas) memiliki nilai lebih kecil dari 10.

\section{Uji Heterokedastisitas}

Uji heterokedastisitas bertujuan untuk menguji apakah dalam model regresi terjadi ketidaksamaan variance dari residual satu pengamatan ke pengamatan yang lain. Jika variance dari residual satu pengamatan ke pengamatan lain tetap, maka disebut homokedastisitas dan jika berbeda disebut heterokedastisitas. 
Habir, H.

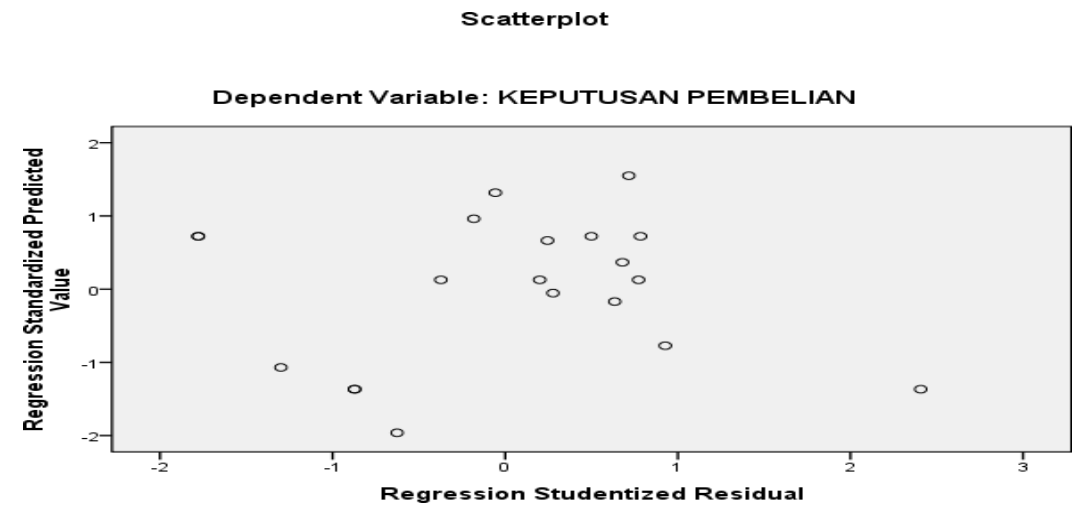

Gambar. 2 Hasil Uji Heterokedastisitas

Jika tidak ada pola yang jelas, serta titik-titik menyebar di atas dan di bawah angka 0 pada sumbu Y, maka tidak terjadi heterokedastisitas, maka dapat dilihat bahwa titik sebaran data tidak membentuk pola yang jelas, serta titik-titik menyebar di bawah dan di atas angka 0 pada sumbu Y, maka dapat disimpulkan bahwa tidak terjadi heterokedastisitas.

\section{Uji Regresi Linear Berganda}

Tabel 2

Hasil Perhitungan Regresi

\begin{tabular}{|c|c|c|c|c|c|c|}
\hline \multirow[b]{2}{*}{ Model } & & \multicolumn{2}{|c|}{$\begin{array}{l}\text { Unstandardized } \\
\text { Coefficients }\end{array}$} & \multirow{2}{*}{$\begin{array}{c}\text { Standardized } \\
\text { Coefficients } \\
\text { Beta }\end{array}$} & \multirow[b]{2}{*}{$\mathrm{t}$} & \multirow[b]{2}{*}{ Sig. } \\
\hline & & B & Std. Error & & & \\
\hline & nstant) & 3.573 & 2.571 & & 1.390 & .183 \\
\hline & a Merek & .475 & .431 & .249 & 1.104 & .002 \\
\hline & rd of Mouth & .591 & .469 & .284 & 1.259 & .087 \\
\hline $\mathrm{R}$ & $=0,417$ & itung & $=1.790$ & & & \\
\hline R-Squar & $=0,174$ & & $=0,000$ & & & \\
\hline
\end{tabular}

Persamaan di atas, memperlihatkan bahwa tanpa adanya variabel bebas yaitu citra merek dan word of mouth (WoM), maka Keputusan Pembelian motor Yamaha di dealer di Kota Bungku adalah menjadi sebesar 3.573 satuan. Koefisien regresi $\mathrm{X}_{1}$ sebesar 0.475 , menunjukkan bahwa setiap ada perubahan variabel produk $\left(\mathrm{X}_{1}\right)$ sebesar satu satuan dan variabel lain tetap, maka akan meningkatkan Keputusan Pembelian motor Yamaha di dealer di Kota Bungku. Koefisien regresi $\mathrm{X}_{2}$ sebesar 0.591, menunjukkan bahwa setiap ada perubahan variabel WoM $\left(\mathrm{X}_{2}\right)$ sebesar satu satuan dan variabel lain tetap, maka akan meningkatkan Keputusan Pembelian motor Yamaha di Kota Bungku.

Selanjutnya, koefisien determinasi memperlihatkan nilai $\mathrm{R}$-Square $=0.174$, Hal ini mengindikasikan bahwa variabel citra merek $\left(\mathrm{X}_{1}\right)$, WoM $\left(\mathrm{X}_{2}\right)$, berpengaruh terhadap Keputusan Pembelian motor yamaha di Kota Bungku sebesar 0.172 atau 17,2\%, dan selebihnya dipengaruhi oleh variabel lain yang tidak diteliti sebesar 82,8\% (100-17,2\%).

\section{Uji Simultan (Uji F)}

Analisis varian ini dapat diperoleh pengertian tentang bagaimana pengaruh sekelompok variabel bebas secara bersama-sama (simultan) terhadap variabel terikat. Hasil Tabel di bawah menunjukkan 
bahwa nilai signifikan $\mathrm{F}=0.000<=0.05$, maka dengan demikian dapat dinyatakan bahwa secara bersama-sama (simultan) variabel citra merek $\left(\mathrm{X}_{1}\right)$, WoM $\left(\mathrm{X}_{2}\right)$ berpengaruh terhadap Keputusan Pembelian (Y) motor Yamaha di Kota Bungku.

Tabel 3

Hasil Uji Simultan

\begin{tabular}{|l|c|c|}
\hline \multicolumn{1}{|c|}{ Model } & F & Sig. \\
\hline Regression & 1.790 & $.000^{\mathrm{a}}$ \\
Residual & & \\
Total & & \\
\hline
\end{tabular}

\section{Uji Parsial (Uji t)}

Tabel 4

Hasil Uji Parsial

\begin{tabular}{|l|r|r|}
\hline \multicolumn{1}{|c|}{ VARIABEL } & T & Sig. \\
\hline (Constant) & 1.390 & .183 \\
\hline Citra Merek & 1.104 & .002 \\
\hline Word of Mounth & 1.259 & .087 \\
\hline
\end{tabular}

a. Citra merek $\left(\mathrm{X}_{1}\right)$

Hipotesis yang diajukan adalah variabel citra merek $\left(\mathrm{X}_{1}\right)$ berpengaruh signifikan terhadap Keputusan Pembelian motor yamaha di Kota Bungku. Menunjukkan variabel citra merek $\left(\mathrm{X}_{1}\right)$ diperoleh nilai signifikan $\mathrm{t}$ (Sig. $\mathrm{t})=0.002<0.05$, sehingga dapat dinyatakan bahwa variabel citra merek $\left(\mathrm{X}_{1}\right)$ mempunyai pengaruh yang signifikan terhadap keputusan pembelian.

b. Word of mouth $\left(\mathrm{X}_{2}\right)$

Hipotesis yang diajukan adalah variabel WoM $\left(\mathrm{X}_{2}\right)$ berpengaruh signifikan terhadap Keputusan Pembelian motor yamaha di Kota Bungku. Berdasarkan Tabel di atas, menunjukkan variabel harga $\left(\mathrm{X}_{2}\right)$ diperoleh nilai signifikan $\mathrm{t}(\mathrm{Sig} . \mathrm{t})=0.087>0.05$, sehingga dapat dinyatakan bahwa variabel WoM $\left(\mathrm{X}_{2}\right)$ berpengaruh tidak signifikan terhadap Keputusan Pembelian.

\section{KESIMPULAAN DAN SARAN}

\section{Kesimpulan}

1. Citra Merek dan Word of Mouth secara bersama-sama(simultan) berpengaruh terhadap Keputusan Pembelian Motor Yamaha di delaer CV Makmur Mandiri di Bungku Tengah Kabupaten Morowali.

2. Citra Merek berpengaruh signifikan terhadap keputusan pembelian sepeda Motor Yamaha di Bungku Tengah Kabupaten Morowali.

3. Word of Mouth berpengaruh tidak signifikan terhadap keputusan pembelian sepeda Motor Yamaha di Bungku Tengah Kabupaten Morowali.

\section{Saran}

1. Disarankan kepada perusahaan agar lebih memperhatikan dan meningkatkan indikator Citra Merek khususnya pada indikator-indikator yang mendaptkan nilai rendah seperti indikator melayani dan popular dan mempertahan indikator yang mendapatkan nilai tinggi menurut persepsi responden seperti concern. 
Habir, $\mathrm{H}$.

2. Untuk variabel Word of Mouth agar meningkatkan indikator membicarakan dan mendorong yang mendapat nilai rendah menurut persepsi responden. Meningkatkan Word of Mouth di lingkungan masyarakat agar informasi tentang produk yang di pasarkan dapat di kenal luas, berhubung variabel Word of Mouth pada penelitian ini tidak berpengaruh signifikan terhadap keputusan pembelian dan untuk Indikator yang sudah di anggap bagus sebaiknya di pertahankan atau mungkin lebih di tingkatkan seperti memberikan informasi.

3. Untuk peneliti selanjutnya di sarankan untuk menambah variabel lain agar lebih luas dalam penelitiannya dan tidak terpaku hanya pada tiga variabel tersebut.

\section{REFERENSI}

Ahmed, (2004), The effect of Brend Image and Brand Identification on Brand Love Purchase Decision Making: The Role of WOM.

Harison-Walker. (2001).“The Measurement of word of mouth Comunication and An Investigation of Servis Quality and Costumer Commitment As Potensial Antecents.

Jalivand dan Samiei. (2012). Analisis Pengaruh Citra Merek Terhadap Keoutusan Pembelian Sepeda Motor Yamaha.

Ismani. (2008). Pengaruh Citra Merek. FISIP.UI

Kotler. (2009). Manajemen Pemasaran 1,Edisi ketiga belas. Jakarta: Erlangga.

Peter, Paul J. dan Jerry C. Olson. (2013). Perilaku Konsumen dan Strategi Pemasaran. Jilid 1 Ed. 9. Dialihbahasakan oleh Diah Tantri Dwiandani. Jakarta: Salemba Empat.

Ririn, T.R., dan Mastuti, H.A. (2011). Manajemen Pemasaran Jasa. Bogor: Ghalia Indonesia.

Suhartono. (2010). Metode Penelitian Kuantatif Kualitatif dab $R \& D$, Bandung: Alfabeta.

Tjiptono, Fandi. (2012). Pemasaran Strategic. Yogyakarta: ANDI. 